ISSN No. 0974-035X

An indexed refereed \& peer-reviewed journal of higher education

Towards Excellence

UGC-HUMAN RESOURCE DEVELOPMENT CENTRE

Gujarat University, Ahmedabad-380009, Gujarat, India

\title{
ARE WE READY FOR NEXT ERA OF TECHNO-DIGITAL MARKETING? - MEASURING EFFECTIVENESS OF EXTENDED REALITY (XR) FOR INTEGRATED MARKETING COMMUNICATION
}

\author{
Mr. Ashit Desai
}

\begin{abstract}
While old fashioned standalone Integrated Marketing Communication (IMC) tools are trailing their effectiveness, integration of Extended Reality (XR) is a new hope for promising future of marketing. XR is an umbrella term encapsulating Augmented Reality (AR), Virtual Reality (VR) and Mixed Reality (MR). Today XR is ground-breaking new ways to interact with digital content. Techno-Digital advancements in recent time has successfully brought customer from physical store to e-store, from general outdoor or print advertisement to personalized and interest-based communication. XR is bridging a gap between physical and digital world.

Present research paper emphasizes on audience's perception on XR in terms of advantages and threats of XR followed by measuring effectiveness of XR. The main objective of this paper is to study readiness of XR technology for Marketing based on primary data of 500 respondents collected through structured questionnaire. Present study concludes with limitation and further research scope in subject discipline.
\end{abstract}

Key Words: Extended Reality (XR), Augmented Reality (AR), Virtual Reality (VR), Techno-Digital Marketing Communication

\section{Introduction}

Smartphone technologies have grown rapidly and reached to peak in recent time(Fowler, 2018). The major technology companies like -Apple, Amazon, Microsoft and Google are working on smartphone for futuristic technologies: Augmented Reality (AR), Virtual Reality (VR), Mixed Reality (MR), Internet of Things (IoT) and Artificial Inelegancy (AI).

Many industries including but not limited to tourism (Griffin, Giberson, Lee, Guttentag, \& Kandaurova, 2017); retail (Bonetti, Warnaby, \& Quinn, 2017); education (Merchant, Goetz, Cifuentes, Keeney-Kennicutt, \& Davis, 2014); entertainment(Lin \& Tao, 2017); healthcare (Freeman, et al., 2017); have initiated to adopt Extended Reality (XR), which is an umbrella term encapsulating AR, VR and MR (Milgram, 1994). Though potential of XR technology has not been fully explored, but pioneering projects across industries are leading the way to show 
the potential of XR. The concept of XR was evolved from gaming and entertainment and started being used for marketing as tool. XR not only enhances self-simulation product or service experiences, but also provides unique sense of presence such that real and immersive environment becomes undistinguished (Suh \& Prophet, 2018).

Referring to available literature and recent work from technology developers of XR, present research was inspired to explore further on XR for Integrated Marketing Communication (IMC) practices, being focused on measuring effectiveness of XR on the bases of primary data collected through structured questionnaire of 500 respondents and backed by academic and industry literature.

\section{BACKGROUND}

\section{Extended Reality (XR)}

$\mathrm{XR}$, as a firm terminology was evolved in recent years, therefore academically defining $\mathrm{XR}$ is difficult. However, AR, VR and MR are referred to represent XR by industry experts. $\mathrm{XR}$ has been defined as "an umbrella term encapsulating $\mathrm{AR}, \mathrm{VR}, \mathrm{MR}$, and everything in between"(Leland, 2017). According to IDC, worldwide spending on AR and VR only are estimated to grow to 72.8 billion US dollar by 2024 , while MR is at its early stage (IDC, 2020). Figure 1 represents differentiating outline of XR, AR, VR and MR

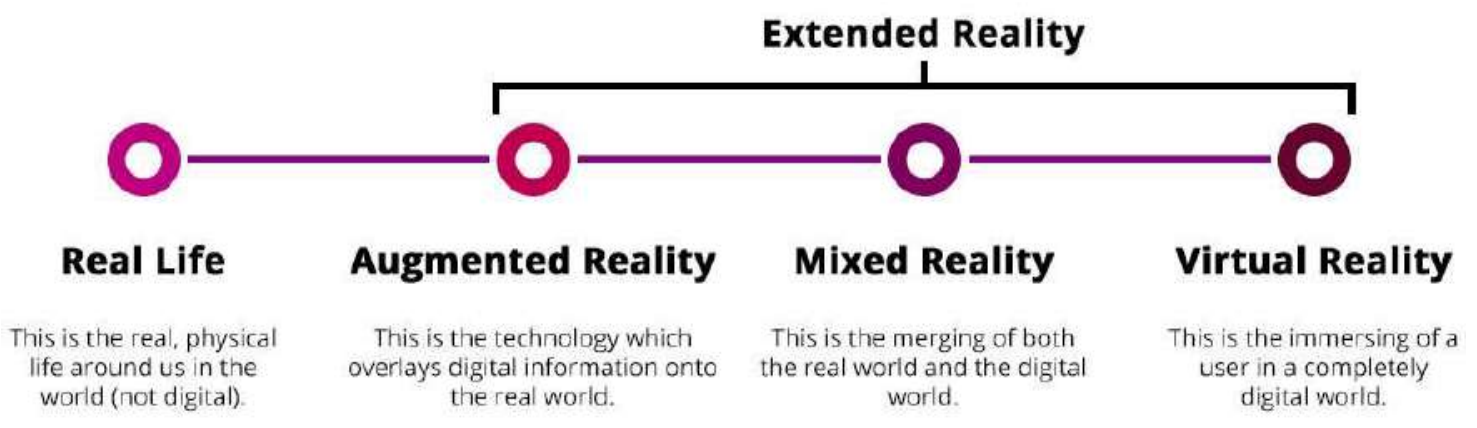

Fig. 1. Differentiating outline of XR, AR, VR and MR

\section{Augmented Reality (AR)}

The concept of AR was introduced by Sutherland in late 60s(Sutherland, 1968). With introduction of computers during 90s AR started being adopted as technology and gained recognition for further research(Starner et al., 1997). AR is conventionally defined as a technology that superimposes virtual environment over real environment. Google Translate mobile app is a widely used and suitable example of AR to be quoted. As Defined by Azuma "AR is a combination of one or more virtual objects overlayed on real objects so as to interact virtual incrustations and physical environment simultaneously. Virtual incrustations must be registered in three-dimensional space"(Azuma, 1997).

Commonly smart devices like smartphones and tablets are used to experience AR. Pokemon Go and Ingress are most hyped AR based mobile games. Lacoste AR mobile app LCST allows customers to virtually try on shoes. The app also creates AR experiences with window displays, in-store signage, and promotional postcards (Alexandra Sheehan, 2018). BMW uses AR friendly brochures to deliver real-life look and feel experience (BMW, 2019). 
Google Maps is rolling out a new feature called "Live View". Google Map's "Live View" uses AR to display virtual signposts and directions in the real world, which shall make it easier for customer to find their desired brand (Google, 2019).

\section{Virtual Reality (VR)}

VR is a kind of more familiar term compared to AR and MR. VR enables users to experience a virtual environment that physically doesn't exists. Though VR as a term evolved during $80 \mathrm{~s}$, VR as a concept was rooted back in 60 s when Ivan Sutherland created the first interactive visualization helmet named as "Incredible Helmet" or "Sword of Damocles"(Sutherland, 1968). This are said to be the first invention of Head Mounted Devices (HMD).

VR can be defined as "An alternative world where digitally generated objects large in numbers are imported and with which the interaction is performed using a wearable device"(Berg \& Vance, 2017). VR makes "different cognitive interactions possible in a digital artificial world, therefore immersing users into imaginary worlds"(Fuchs et al., 2011).

Tata Motors at the Geneva Motor Show used VR for virtual test drive (Tata ELXSI, 2016). A cookie brand Oreo launched a $360^{\circ}$ interactive virtual factory tour using VR(Mbryonic, 2018).

\section{Mixed Reality (MR)}

MR is also referred as Hybrid Reality as it blends virtual environment with real environment. As defined by Hughes et al. "MR combines the AR and VR technologies in order to produce new environments and visualizations where physical and digital objects can co-exist (real objects added to virtual environment, virtual objects to the real world or even virtual objects to virtual world)"(Hughes et al., 2005). Microsoft HoloLens, Magic Leap, Epson Moverio, Google Glass, Vuzix Blade, Raptor, Third Eye, Kopin Solos, Toshiba Dyna Edge, Snap Spectacles are some of the smart devices based on MR(Software Testing Help, 2020).

Rolex, a premium watch brand executed its MR friendly print advertisment by enhancing virtual try-on experience (Charlotte Yianni, 2018). MR has a potential to equip after sales services with "Virtual Assistance" and "Self Help" services. BMW MR car repair, Microsoft HoloLens for car repair and I-Mechanic (Yariv Levski, 2019); are some of the reallife examples of MR based after sales services.

\section{RESEARCH OBJECTIVES}

By reviewing discipline related literature, a research gap was found whereby on one side giant tech specialists like Google, Microsoft, HTC, Epson, Toshiba etc. are exploring XR whereas only few brands have adopted XR as marketing tool. A strong systematic study was needed to understand and explore awareness of XR, usage of XR, worth and worst of XR and to measure effeteness of XR as a whole. Outcome are based on audience's perspectives, as entire study was audience centric and conducted to attain below listed objectives. 
1. To study awareness of XR

2. To study usage of XR

3. To study and measure advantages and associated threats of XR

4. To study and measure effectiveness of XR

\section{METHODOLOGY AND APPROACH}

Present research followed descriptive research design based on responses collected through structured questionnaire of 500 respondents. Non-probability convenient sampling technique was used for data collection.

A construct consisting three sets of benefits and one set of associated threats of XR was developed based on secondary data. Figure 2 represents structure of construct.

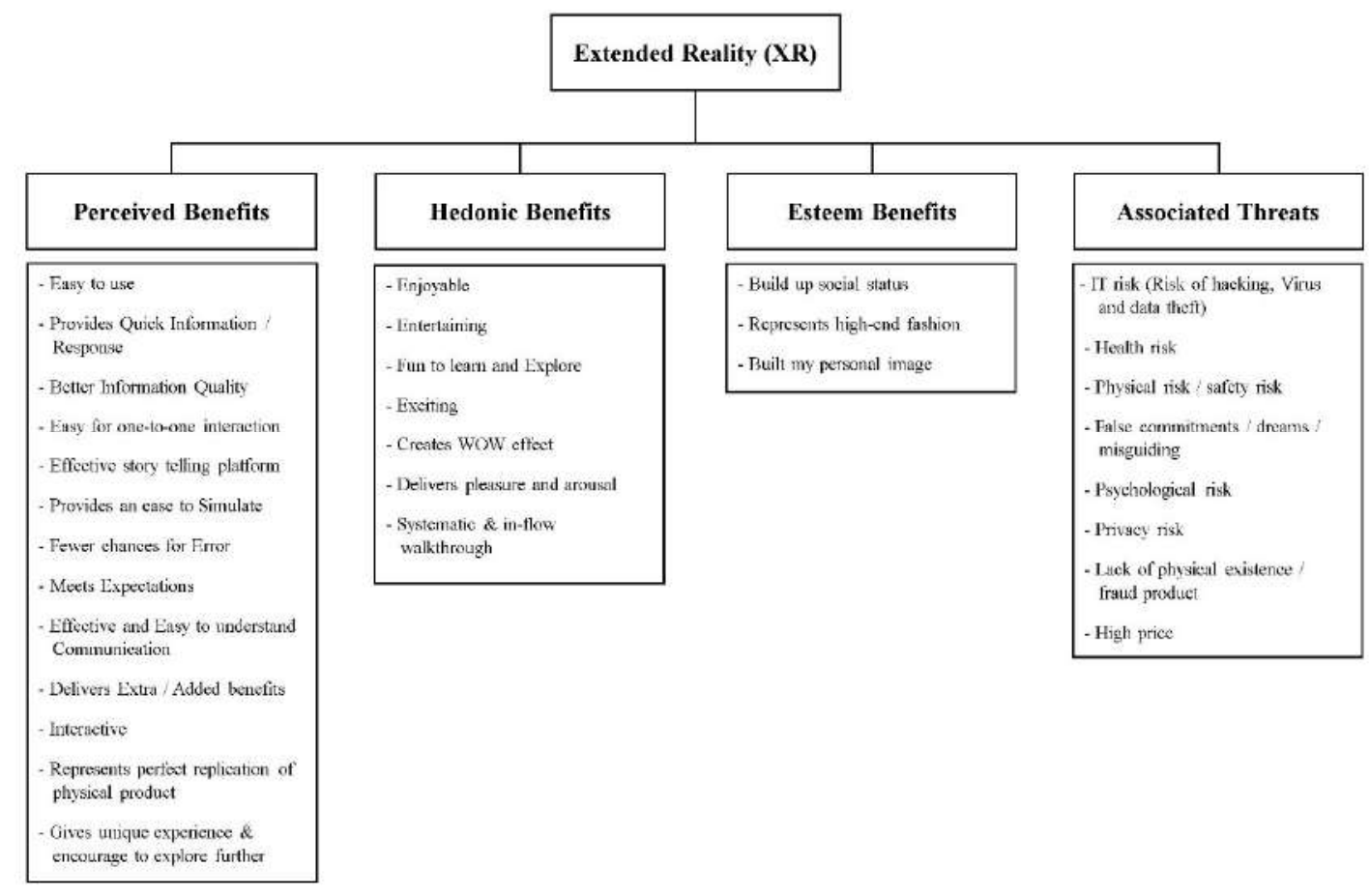

Fig.2. Structure of Construct

A mix of single select, multiple select and five-point Likert rating scale ranging from strongly agree to strongly disagree questions were asked to respondents. Along with these questions, research instrument initiated with an audio-visual screening question. Table 1 summarizes demographic profile of respondents. 
Towards Excellence: An Indexed, Refereed \& Peer Reviewed Journal of Higher Education /

Mr.AshitDesai/ Page 608-619

\begin{tabular}{|c|c|c|}
\hline \multicolumn{3}{|c|}{ Gender } \\
\hline & Frequency & Percent \\
\hline Male & 412 & 82.4 \\
\hline Female & 88 & 17.6 \\
\hline Total & 500 & 100.0 \\
\hline \multicolumn{3}{|c|}{ Age } \\
\hline & Frequency & Percent \\
\hline Below 20 years & 7 & 1.4 \\
\hline 21 to 30 years & 173 & 34.6 \\
\hline 31 to 40 years & 214 & 42.8 \\
\hline 41 to 50 years & 87 & 17.4 \\
\hline Above 50 Years & 19 & 3.8 \\
\hline Total & 500 & 100.0 \\
\hline \multicolumn{3}{|c|}{ Education Qualification } \\
\hline & Frequency & Percent \\
\hline Schooling & 3 & 0.6 \\
\hline Graduate & 159 & 31.8 \\
\hline Post Graduate & 215 & 43.0 \\
\hline Professional & 71 & 14.2 \\
\hline Other & 52 & 10.4 \\
\hline Total & 500 & 100.0 \\
\hline \multicolumn{3}{|c|}{ Occupation } \\
\hline & Frequency & Percent \\
\hline Student & 57 & 11.4 \\
\hline Service & 174 & 34.8 \\
\hline Self-employed/Businness & 181 & 36.2 \\
\hline Professional & 69 & 13.8 \\
\hline Retired & 6 & 1.2 \\
\hline Home Maker & 13 & 2.6 \\
\hline Total & 500 & 100.0 \\
\hline \multicolumn{3}{|c|}{ Annual Family Income (in Rs.) } \\
\hline & Frequency & Percent \\
\hline Below 5 Lakh & 12 & 2.4 \\
\hline 5 to $10 \mathrm{Lakh}$ & 148 & 29.6 \\
\hline 10 to $15 \mathrm{Lakh}$ & 178 & 35.6 \\
\hline 15 to $20 \mathrm{Lakh}$ & 100 & 20.0 \\
\hline 20 to $25 \mathrm{Lakh}$ & 30 & 6.0 \\
\hline Above 25 Lakh & 32 & 6.4 \\
\hline Total & 500 & 100.0 \\
\hline
\end{tabular}

Table 1 - Demographic Profile of Respondents 


\section{ANALYSIS AND DISCUSSION}

Based on data collected as per developed construct as shown in figure 2, data was further processed through SPSS to analyses and attain research objectives.

\section{Reliability Testing}

Internal consistency of the data is typically measured using Cronbach's Alpha $(\alpha)$. Cronbach's Alpha ranges from 0 to 1 , with higher values indicating greater internal consistency and ultimately reliability. Result of reliability testing is shown in table 2 representing Cronbach's Alpha $(\alpha)$ value of determinants. The Cronbach's Alpha $(\alpha)$ value exceeds 0.70 for each determinant, which represents highly reliable items to be included in scale.

\begin{tabular}{|l|c|c|}
\hline \multicolumn{1}{|c|}{ Determinants } & Cronbach's Alpha ( $\boldsymbol{\alpha})$ & No. of Items \\
\hline Perceived Benefits & 0.978 & 13 \\
Hedonic Benefits & 0.967 & 7 \\
Esteem Benefits & 0.935 & 3 \\
Associated Threats & 0.978 & 8 \\
\hline
\end{tabular}

Table 2 - Cronbach's Alpha $(\alpha)$ value of Determinants.

\section{Awareness and Usage of AR, VR, MR and XR}

In order to attain objective 1 - To study awareness of XR and objective 2 - To study usage of XR, Data was collected by asking single choice multiple select question. Table 3 represents outcome of data collected to attain objective 1 and 2.

\begin{tabular}{|l|r|r|r|r|}
\hline & \multicolumn{2}{|c|}{ Awareness } & \multicolumn{2}{c|}{ Usage } \\
\cline { 2 - 5 } & Frequency & Percentage & Frequency & Percentage \\
\hline Augmented Reality (AR) & 297 & $59.4 \%$ & 109 & $21.8 \%$ \\
Virtual Reality (VR) & 366 & $73.2 \%$ & 124 & $24.8 \%$ \\
Mixed Reality (MR) & 141 & $28.2 \%$ & 50 & $10.0 \%$ \\
Extended Reality (XR) & 372 & $74.4 \%$ & 158 & $31.6 \%$ \\
\hline \multicolumn{1}{|c}{ Total } & $\mathbf{5 0 0}$ & $\mathbf{1 0 0 . 0} \%$ & $\mathbf{5 0 0}$ & $\mathbf{1 0 0 . 0} \%$ \\
\hline
\end{tabular}

Table 3 - Awareness and Usage of AR, VR, MR and XR

Data represents majority of the respondents are more aware about XR being at $74 \%$ and VR being at $73.2 \%$ followed by AR being at $59.4 \%$ and MR being at $28.2 \%$ respectively. Whereas in terms of usage, same scenario derived; having XR being at $31.6 \%$ and VR being at $24.8 \%$ followed by AR being at $21.8 \%$ and MR being at $10 \%$ respectively.

\section{Perceived Benefits of XR}

Table 4 represents outcome of 13 items under construct of perceived benefits of XR. A question was asked to respondents on five-point Likers scale, to partially attain objective 3 To study and measure advantages and associated threats of XR. A mean value ( $\square$ ) was calculated for each item so as to have ease in data analysis. Mean value lays with in chosen scale i.e., five-point Likert scale ranging from strongly agree to strongly disagree. 
Towards Excellence: An Indexed, Refereed \& Peer Reviewed Journal of Higher Education /

Mr.AshitDesai/ Page 608-619

\begin{tabular}{|l|r|r|r|r|r|r|}
\hline Perceived Benefits of XR & $\begin{array}{c}\text { Strongly } \\
\text { Agree }\end{array}$ & Agree & Neutral & Disagree & $\begin{array}{r}\text { Strongly } \\
\text { Disagree }\end{array}$ & $\begin{array}{r}\text { Mean } \\
\text { value }\end{array}$ \\
\hline Easy to use & $38.6 \%$ & $46.6 \%$ & $9.4 \%$ & $4.4 \%$ & $1.0 \%$ & 4.17 \\
Quick information and & $32.0 \%$ & $45.6 \%$ & $13.8 \%$ & $7.4 \%$ & $1.2 \%$ & 4.00 \\
response & $29.8 \%$ & $41.8 \%$ & $17.2 \%$ & $7.8 \%$ & $3.4 \%$ & 3.87 \\
Quality information & $27.4 \%$ & $44.4 \%$ & $16.2 \%$ & $9.0 \%$ & $3.0 \%$ & 3.84 \\
One to one interaction & $28.4 \%$ & $44.0 \%$ & $16.4 \%$ & $7.4 \%$ & $3.8 \%$ & 3.86 \\
Effective story telling & $27.4 \%$ & $43.8 \%$ & $15.0 \%$ & $10.0 \%$ & $3.8 \%$ & 3.81 \\
Easy simulation & $25.2 \%$ & $43.6 \%$ & $16.0 \%$ & $10.6 \%$ & $4.6 \%$ & 3.74 \\
Error Free & $23.4 \%$ & $45.6 \%$ & $15.8 \%$ & $10.6 \%$ & $4.6 \%$ & 3.73 \\
Meeting expectations & $35.2 \%$ & $39.0 \%$ & $14.2 \%$ & $8.4 \%$ & $3.2 \%$ & 3.95 \\
Easy to understand & $26.6 \%$ & $41.2 \%$ & $19.0 \%$ & $8.2 \%$ & $5.0 \%$ & 3.76 \\
Extra/added benefits & $35.2 \%$ & $37.6 \%$ & $16.6 \%$ & $6.8 \%$ & $3.8 \%$ & 3.94 \\
Interactive & $45.4 \%$ & $34.2 \%$ & $11.2 \%$ & $6.0 \%$ & $3.2 \%$ & 4.13 \\
Replication of actual & $39.8 \%$ & $37.6 \%$ & $11.2 \%$ & $8.2 \%$ & $3.2 \%$ & 4.03 \\
product & & & & & \\
Encourage to explore & & & & & & \\
further & & &
\end{tabular}

Table 4 - Perceived Benefits of XR

Among 13 items, XR was found highly easy to use having mean value ( $\square$ ) 4.17, followed by usefulness to represent replication of actual product having mean value ( $\square$ ) 4.13 which represents respondent's concern as "agree". The lowest mean value ( $\square$ ) 3.73 and 3.74 represented XR for meeting expectations and being error free respectively. However, these values also represent respondent's concern as "agree".

\section{Hedonic Benefits of XR}

Hedonic benefits of XR construct contained 8 items. Table 5 represents outcome of data derived by asking five-point Likers scale question, designed to partially attain objective 3 - To study and measure advantages and associated threats of XR. Alike perceived benefits of XR construct, here also mean value $(\square)$ was calculated for each item measured on scale of one to five, ranging from strongly agree to strongly disagree.

\begin{tabular}{|l|r|r|r|r|r|r|}
\hline Hedonic Benefits of XR & $\begin{array}{c}\text { Strongly } \\
\text { Agree }\end{array}$ & Agree & Neutral & Disagree & $\begin{array}{c}\text { Strongly } \\
\text { Disagree }\end{array}$ & $\begin{array}{c}\text { Mean } \\
\text { value }\end{array}$ \\
\hline Enjoyable & $47.8 \%$ & $35.8 \%$ & $9.2 \%$ & $6.6 \%$ & $0.6 \%$ & 4.24 \\
Entertaining & $40.4 \%$ & $40.2 \%$ & $8.8 \%$ & $7.2 \%$ & $3.4 \%$ & 4.07 \\
Fun to learn & $39.8 \%$ & $32.8 \%$ & $14.8 \%$ & $8.0 \%$ & $4.6 \%$ & 3.95 \\
Exciting & $32.2 \%$ & $40.4 \%$ & $14.8 \%$ & $7.0 \%$ & $5.6 \%$ & 3.87 \\
WOW effect & $20.4 \%$ & $40.6 \%$ & $25.2 \%$ & $7.6 \%$ & $6.2 \%$ & 3.61 \\
Pleasure and arousal & $24.8 \%$ & $39.4 \%$ & $21.8 \%$ & $8.2 \%$ & $5.8 \%$ & 3.69 \\
In flow walkthrough & $52.8 \%$ & $27.2 \%$ & $11.6 \%$ & $5.8 \%$ & $2.6 \%$ & 4.22 \\
\hline
\end{tabular}

Table 5 -Hedonic Benefits of XR 
XR was found highly enjoyable at mean value ( $\square$ ) 4.24 followed by inflow walkthrough at mean value ( $\square$ ) 4.22 representing respondent's concern as "agree". The lowest mean value ( $\square$ ) was derived for XR creating WOW effect at 3.61, followed by pleasure and arousal at mean value $(\square)$ of 3.69 , which are again respondent's concern towards "agree".

\section{Esteem Benefits of XR}

In continuation to perceived benefits and hedonic benefits of XR constructs, esteem benefits of XR construct were also followed same design pattern. Table 6 represents data outcome objected to partially attain objective 3 - To study and measure advantages and associated threats of XR.

\begin{tabular}{|l|r|r|r|r|r|r|}
\hline \multicolumn{1}{|c|}{ Esteem Benefits of XR } & $\begin{array}{c}\text { Strongly } \\
\text { Agree }\end{array}$ & Agree & Neutral & Disagree & $\begin{array}{c}\text { Strongly } \\
\text { Disagree }\end{array}$ & $\begin{array}{c}\text { Mean } \\
\text { value }\end{array}$ \\
\hline Social Status & $8.4 \%$ & $56.6 \%$ & $22.2 \%$ & $7.6 \%$ & $5.2 \%$ & 3.55 \\
High-end Fashion & $26.8 \%$ & $45.6 \%$ & $16.6 \%$ & $5.8 \%$ & $5.2 \%$ & 3.83 \\
Personal Image & $18.2 \%$ & $41.0 \%$ & $27.6 \%$ & $5.8 \%$ & $7.4 \%$ & 3.57 \\
\hline
\end{tabular}

Table 6 - Esteem Benefits of XR

Out of 3 items measured on five-point Likert scale, XR as high-end fashion accessory derived with highest mean value ( $\square$ ) 3.83 followed by XR building personal image with mean value ( $\square$ ) 3.57 and XR for increasing social status with mean value ( $\square$ ) 3.55, all towards respondents concern of "agree".

\section{Associated Threats of XR}

A construct of associated threats of XR was designed having 8 items. Table 7 represents the outcome of data collected by asking five-point Likert scale question, objected to partially attain objective 3 - To study and measure advantages and associated threats of XR. Considering unity of scale, data was measured on same scale of previous constructs, i.e., five points ranging from strongly agree to strongly disagree. Unlike previous constructs, instead of higher mean value ( $\square$ ), lowest mean value ( $\square$ ) is to be interpreted as more favorable as high value of benefits and low value of threats are preferred.

\begin{tabular}{|l|r|r|r|r|r|r|}
\hline Associated Threats of XR & $\begin{array}{c}\text { Strongly } \\
\text { Agree }\end{array}$ & Agree & Neutral & Disagree & $\begin{array}{c}\text { Strongly } \\
\text { Disagree }\end{array}$ & $\begin{array}{c}\text { Mean } \\
\text { value }\end{array}$ \\
\hline IT Risk & $18.6 \%$ & $26.4 \%$ & $19.6 \%$ & $19.2 \%$ & $16.2 \%$ & 3.12 \\
Health Problems & $6.2 \%$ & $14.0 \%$ & $19.8 \%$ & $29.6 \%$ & $30.4 \%$ & 2.36 \\
Physical and safety Risk & $5.4 \%$ & $13.0 \%$ & $21.0 \%$ & $28.6 \%$ & $32.0 \%$ & 2.31 \\
False Commitments and & $8.4 \%$ & $12.8 \%$ & $22.0 \%$ & $27.2 \%$ & $29.6 \%$ & 2.43 \\
Dreams & $5.4 \%$ & $12.2 \%$ & $22.4 \%$ & $29.0 \%$ & $31.0 \%$ & 2.32 \\
Psychological Risk & $10.2 \%$ & $19.2 \%$ & $24.4 \%$ & $19.6 \%$ & $26.6 \%$ & 2.67 \\
Privacy Risk & $8.8 \%$ & $14.6 \%$ & $23.2 \%$ & $27.8 \%$ & $25.6 \%$ & 2.53 \\
Risk of Fraud Product & $8.6 \%$ & $12.4 \%$ & $25.4 \%$ & $28.0 \%$ & $25.6 \%$ & 2.5 \\
High Price & & & & & \\
\hline
\end{tabular}

Table 7 - Associated Threats of XR 
The lowest mean value ( $\square$ ) derived to 2.31 for XR having physical and safety risk, followed by psychological risk of XR at mean value $(\square)$ of 2.32 which represents respondents concern as "disagree". The IT risk of XR and Privacy risk derived with mean values $(\square)$ of 3.12 and 2.63 respectively, representing respondents concern as "neutral".

\section{Factor Score}

As each construct contains multiple items and as all items are measured considering unity of scale for both, advantages and threats, a factor score was calculated using weightage average as per below formula.

$$
\begin{aligned}
\text { Factor Score } & =\frac{\left.\sum \text { (Number of Responses for Each Indicators X Weightage }\right)}{\left.\sum \text { (Number of Indicators X Sample Size }\right)} \\
& =\frac{\sum\left(f_{i} x_{i}\right)}{\sum\left(f_{i}\right)}
\end{aligned}
$$

For instance, table 8 represents calculation of factor score for esteem benefits of XR.

\begin{tabular}{|l|r|r|r|r|r|r|}
\hline \multicolumn{1}{|c|}{ Scale } & $\begin{array}{c}\text { Weightage } \\
\boldsymbol{x i}\end{array}$ & $\begin{array}{c}\text { High-end } \\
\text { fashion }\end{array}$ & $\begin{array}{c}\text { Social } \\
\text { status }\end{array}$ & $\begin{array}{c}\text { Personal } \\
\text { image }\end{array}$ & \multicolumn{1}{c|}{$\boldsymbol{f}_{\boldsymbol{i}}$} & \multicolumn{1}{c|}{$\boldsymbol{f}_{\boldsymbol{i}} \boldsymbol{x}_{\boldsymbol{i}}$} \\
\hline Strongly Disagree & 1 & 26 & 26 & 37 & 89 & 89 \\
Disagree & 2 & 29 & 38 & 29 & 96 & 192 \\
Neutral & 3 & 83 & 111 & 138 & 332 & 996 \\
Agree & 4 & 228 & 283 & 205 & 716 & 2864 \\
Strongly Agree & 5 & 134 & 42 & 91 & 267 & 1335 \\
\hline Total & & $\mathbf{5 0 0}$ & $\mathbf{5 0 0}$ & $\mathbf{5 0 0}$ & $\mathbf{1 5 0 0}$ & $\mathbf{5 4 7 6}$ \\
\hline
\end{tabular}

Table 8 - Factor score of Esteem Benefits of XR

Factor Score (Esteem Benefits of XR) $=\frac{\sum\left(f_{i} x_{i}\right)}{\sum\left(f_{i}\right)}=\frac{5476}{1500}=3.65$

As shown in table 8 , weightage was assigned ranging from 1 to 5 , where highest weightage 5 was assigned to "strongly agree" and 1 is the lowest weight assigned to "strongly disagree" and accordingly for values in between. This weightage was similar for three constructs i.e., perceived benefits of XR, hedonic benefits of XR and esteem benefits of XR. For associated threats of XR, highest weightage 5 was assigned to "strongly disagree" and lowest weightage 1 was assigned to "strongly agree" as in contras to benefits, for threats "strongly disagree" represents favorability. Table 9 represents factor score calculated for each construct. 
Table 9 - Summary of factor Score

\begin{tabular}{|l|l|}
\hline Perceived Benefits & 3.91 \\
Hedonic Benefits & 3.95 \\
Esteem Benefit & 3.65 \\
Associated Threats & 3.47 \\
\hline
\end{tabular}

Factor scores derived for each construct is near to 4, which represents favorability of benefits and associated threats of XR.

\section{Effectiveness of XR}

In order to attain objective 4 - to study and measure effectiveness of XR, effectiveness score of XR was calculated using below formula.

XR Effectiveness $=\frac{\sum(\text { Factor Score })}{\text { Number of Factors }}=\frac{3.91+3.95+3.65+3.47}{4}=\mathbf{3 . 7 5}$

As the value of factor score ranges between 1 to 5, effectiveness score also falls under same boundary of 1 to 5, where 5 represents high level of effectiveness. Effectiveness of XR derived to 3.75 , which represents fairly effectiveness of XR.

\section{CONCLUSION}

Looking to the outcome of present research, XR was found fairly worth. Whereas the worst of XR was found with neutral i.e., not fair as well as not unfair. The overall effectiveness of XR came-out as fairly effective. As the research is based on audience's view, outcome is highly practice and worth for a marketer to be deployed. XR is a futuristic technology, known developer brands - Microsoft, Epson, Google, HTC, Raptor, Toshiba, Samsung etc. are working to expand boundaries of XR. Brands like BMW, Tata, Toyota, Jio, Ikea, Lacoste, Nike, Adidas, Gucci, New York Yankees, Lakme and many more have adopted XR technology for their Integrated Marketing Communication. 
Technology keeps changing at higher pace. And such technical change may limit XR technology. However, XR will not get outdated in near future as its is still in introductory phase. In continuation to subject research, further research can be conducted to bridge the gap of XR effectiveness at various audience touchpoints. Research on XR technology in marketing discipline is said to bring a big change by delivering immersive experience and will make true sense for "try" before you "buy". 


\section{Works Cited}

Alexandra Sheehan. "How These Retailers Use Augmented Reality to Enhance the Customer $\begin{array}{llllllll}\text { Experience." } & 21 & 02 & 2018 . & \text { www.shopify.in. } & 04 & 10 & 2019 .\end{array}$ $<$ https://www.shopify.in/retail/how-these-retailers-are-using-augmented-reality-toenhance-the-customer-experience $>$.

BMW. BMW Apps: Virtual \& Augmented Reality. 2019. $05 \quad 10 \quad 2019$. $<$ https://www.bmw.in/en/topics/owners/bmw-apps/virtual-and-augmentedreality.html>.

Bonetti, Francesca, Gary Warnaby and Lee Quinn. Augmented Reality and Virtual Reality in Physical and Online Retailing: A Review, Synthesis and Research Agenda. Springer, 2017.

Charlotte Yianni. 3 WAYS AUGMENTED REALITY POWERFULLY ENHANCES PRINT CAMPAIGNS. 2703 2018. 0710 2019. <https://www.blippar.com/blog/2018/03/27/3ways-augmented-reality-powerfully-enhances-print-campaigns $>$.

Freeman, D., et al. "Virtual reality in the assessment, understanding, and treatment of mental health disorders." Psychological Medicine (2017): 2393-2400.

Google. Introducing Live View, the new augmented reality feature in Google Maps. 0809 2019. 0610 2019. <https://support.google.com/maps/thread/11554255?hl=en>.

Griffin, Tom, et al. "Virtual Reality and Implications for Destination." 48th Annual Travel and Tourism Research Association (TTRA). Travel and Tourism Research Association, 2017.

Lin, Jih-Hsuan Tammy and Chen-Chao Tao. "So scary, yet so fun: The role of self-efficacy in enjoyment of a virtual reality horror game." New Media \& Society (2017).

Merchant, Zahira, et al. "Effectiveness of virtual reality-based instruction on students' learning outcomes in K-12 and higher education: A meta-analysis." Computers \& Education (2014): 29-40.

Tata ELXSI. Augmented and Virtual Reality: Helping Tata Motors to provide an immersive automotive experience at the Geneva Motor Show. 2016. 05102019. $<\mathrm{https}$ ://tataelxsi.com/industries/automotive/visualization-digital-marketing/arvr.html>.

Yariv Levski. Augmented Reality. 2019. 0710 2019. <https://appreal-vr.com/blog/augmentedreality-car-repair/>.

\section{Mr. Ashit Desai \\ Ph.D. Scholar - GLS University, Ahmedabad ashit21desai@gmail.com, M. 9724058718}

